\title{
Percepções dos estudantes do Ensino Médio sobre os conhecimentos aprendidos nas aulas de Educação Física Escolar
}

\author{
High school students' perceptions of knowledge learned in Physical education classes \\ Percepción de los estudiantes de secundaria del conocimiento aprendido en las clases de \\ Educación Física de la escuela.
}

\author{
Jadeh de Moura Vieira Bastoss, Daniel Teixeira Maldonado ${ }^{\mathrm{II}}$
}

\begin{abstract}
Resumo
O objetivo deste estudo foi compreender as percepções dos estudantes do Ensino Médio que participaram de aulas de Educação Física sobre os conhecimentos que aprenderam durante as aulas desse componente curricular. Para tanto, foi utilizado narrativas escritas de quatro estudantes do Instituto Federal de São Paulo. Os resultados foram interpretados pela análise de conteúdo. Os discentes vivenciaram os gestos das práticas corporais de diferentes culturas, debateram e analisaram os aspectos sociais, econômicos, políticos e históricos relacionados com as manifestações da cultura corporal e refletiram sobre a relação entre a atividade física, a saúde e a qualidade de vida.
\end{abstract}

Palavras-chave: Educação Física Escolar; Ensino Médio; Cultura das Práticas Corporais

\begin{abstract}
The goal of this study was to understand the perception that High School's students who participated in Physical Education classes on the knowledge they learned during classes of this curricular component. To do so, it was used four written narratives of students from Federal Institute of São Paulo. The results were analyzed through the content analysis method. The students experienced the gestures of body practices from different cultures, debated and analyzed the social, economic, political and historical aspects related to the manifestations of body culture and reflected on the relationship between physical activity, health and quality of life.
\end{abstract}

Keywords: Physical Education Classes; High School; Physical Practices Culture

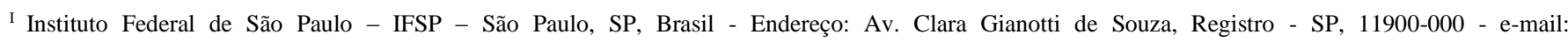
jadeh82@ hotmail.com

II Instituto Federal de Educação, Ciência e Tecnologia - São Paulo, SP, Brasil - e-mail: danieltmaldonado@ yahoo.com.br
} 


\section{Resumen}

El objetivo de este estudio fue comprender las percepciones de los estudiantes de secundaria que participaron en las clases de Educación Física sobre el conocimiento que aprendieron durante las clases de este componente curricular. Para esto, utilizamos narraciones escritas de cuatro estudiantes del Instituto Federal de São Paulo. Los resultados fueron interpretados por análisis de contenido. Los estudiantes experimentaron los gestos de las prácticas corporales, debatieron y analizaron los aspectos sociales, económicos, políticos e históricos relacionados con las manifestaciones de la cultura corporal y reflexionaron sobre la relación entre la actividad física, la salud y la calidad de vida.

Palabras Clave: Educación Física escolar; Escuela Secundaria; Cultura de las Prácticas Corporales

\section{Introdução}

Após a formulação de diferentes propostas pedagógicas, principalmente no início do século XXI, os professores e as professoras de Educação Física passam a publicar relatos sobre os projetos educativos que eles e elas desenvolvem em suas aulas. Muitas dessas experiências educativas possuem como campo de inspiração as perspectivas curriculares crítico-superadora, crítico-emancipatória e cultural (MALDONADO; NEIRA, 2019).

As perspectivas crítico-superadora e crítico-emancipatória surgem na produção intelectual da área, denunciando que as práticas dos professores e professoras transmitiam e mantinham os valores das elites e dos condicionantes capitalistas. Procedimentos de ensino pautados por ações reflexivas e dialogadas sobre o processo de construção das manifestações da cultura corporal, com o objetivo de conscientizar os alunos e alunas sobre os mecanismos de dominação presentes na sociedade, são sugeridos (AGUIAR; NEIRA, 2016).

A proposta crítico-superadora foi apresentada no livro Metodologia do ensino da educação física, de um coletivo de autores, publicado em 1992. Essa perspectiva curricular baseia-se fundamentalmente na pedagogia histórico-crítica desenvolvida por Dermeval Saviani e colaboradores. Esse dispositivo curricular entende que o objeto de conhecimento da Educação Física é a cultura corporal que se concretiza nos seus diferentes temas, que se materializam nas práticas corporais (BRACHT, 1999).

A proposta crítico-emancipatória, que tem como principal formulador o professor Elenor Kunz, foi formulada com fortes influências da pedagogia de Paulo Freire e das análises fenomenológicas do movimento humano. Essa perspectiva parte de uma concepção de movimento dialógica, sendo o movimentar-se humano entendido como uma forma de comunicação com o mundo. Assim, no cotidiano escolar, os docentes precisam tematizar os elementos da cultura do movimento, de forma a desenvolver nos alunos a capacidade de analisar e agir criticamente nessa esfera (BRACHT, 1999). 
No bojo da sociedade pós-moderna, as teorias pós-críticas da educação, principalmente nos estudos culturais e no multiculturalismo crítico, oferecem argumentos para produção de uma nova perspectiva do componente, intitulada currículo cultural. Nessa proposta, os docentes organizam atividades de ensino em que os signos de poder presentes nas brincadeiras, danças, lutas, esportes e ginásticas são analisados pelos alunos e alunas, além de procurar criar condições para o estudo das práticas corporais historicamente marginalizadas (AGUIAR; NEIRA, 2016).

Na perspectiva de Neira (2018), desde 2004, muitos professores e professoras se debruçaram a organizar a sua prática pedagógica inspirados pela fundamentação teórica do currículo cultural, fazendo emergir formulações como mapeamento, vivência, leitura, ressignificação, aprofundamento, ampliação, registro, avaliação, tematização, problematização, justiça curricular, evitar o daltonismo cultural, descolonização do currículo, ancoragem social dos conhecimentos, desconstrução, escrita-currículo, contragolpe social, metáfora da capoeira e etnografia das práticas corporais, que lidos a partir da teorização pós-crítica, configuram essa concepção de ensino.

A teorização curricular crítica e pós-crítica refundou a prática político-pedagógica da Educação Física Escolar, principalmente porque distanciou a fundamentação teórica pautada nas Ciências Naturais que sempre foi hegemônica na área. Dessa forma, Maldonado (2020) defende que os professores e as professoras do componente curricular passaram a interpretar, negociar, traduzir e reorganizar essas teorias nas suas experiências didáticas, possibilitando novas formas de significação dos estudantes sobre essas aulas no cotidiano escolar.

Especificamente nos Institutos Federais, que se consolidaram no cenário nacional com uma política pública educacional que valoriza a carreira docente, uma série de experiências educativas foram publicadas na literatura da área de Educação Física sobre a prática político-pedagógica dos professores e das professoras desse componente curricular que atuam nessas instituições de ensino, tendo como inspiração as teorias críticas e pós-críticas em currículo.

Nesse contexto, o trekking foi tematizado no CEFET-MG - campus Curvelo (SILVA, 2018), os esportes alternativos desenvolvidos no CEFET - MG - campus Nepomuceno (BARRA, 2018), os aspectos sociais das danças problematizadas no Instituto Federal de Minas Gerais - campus Ouro Branco (TAVARES, 2018) e no Instituto Federal de São Paulo - campus Capivari (DINIZ, 2018), os aspectos culturais dos jogos e das brincadeiras debatidos no Instituto Federal de São Paulo - campus Cubatão (OLIVEIRA; MALDONADO, 2018) e as práticas corporais da cultura afro-brasileira vivenciadas no Instituto Federal do Pará - campus Tucuruí (ALENCAR FILHO, 2018). 
Assim sendo, já temos evidências na literatura que os professores e as professoras de Educação Física que lecionam nos Institutos Federais estão desenvolvendo projetos educativos inspirados pelas propostas curriculares mais progressistas do componente curricular. Entretanto, poucas pesquisas foram realizadas com os estudantes que estão participando dessas aulas, com a intenção de compreender quais conhecimentos esses jovens estão acessando. Assim, surge a seguinte pergunta. Quais conhecimentos são aprendidos pelos estudantes do Ensino Médio durante as aulas de Educação Física?

Portanto, o objetivo deste estudo foi compreender as percepções dos estudantes do Ensino Médio sobre os conhecimentos que aprenderam durante as aulas de Educação Física Escolar.

\section{Procedimentos Metodológicos}

Para atingir os objetivos propostos neste estudo foi realizada uma pesquisa qualitativa com método do tipo exploratório descritivo (GIL, 2008). A preocupação dos estudiosos que se dedicam em produzir pesquisas qualitativas é compreender o outro e como os sujeitos significam o mundo e a vida, descrever e compreender a diversidade das experiências humanas e as subjetividades existentes nessas relações (MOLINA NETO; MOLINA, 2010).

Portanto, o pesquisador qualitativo é parte do problema de investigação, pois ele atua como construtor de cenários, práticas e imagens interpretativas que por ele articuladas representam o fenômeno estudado para organizar a versão da história que será narrada (MOLINA NETO; MOLINA, 2010).

Nesse contexto, após ministrar aulas de Educação Física para uma turma do Ensino Médio integrado ao Ensino Técnico, do Instituto Federal de São Paulo - campus São Paulo, tivemos a oportunidade de tematizar as ginásticas, as danças, as lutas, os esportes, os jogos e as brincadeiras de diferentes culturas, além de problematizar os marcadores sociais relacionados com essas práticas corporais, por um período de dois anos. Quando os estudantes estavam no último ano desse ciclo de escolarização, cinco jovens foram convidados para participar deste estudo, porque se envolveram efetivamente nas aulas do componente curricular durante esse tempo, a partir da nossa percepção.

Para obtenção das informações necessárias para a realização do estudo foi solicitado que os discentes produzissem memoriais descritivos, de acordo com as orientações de Silva e Diehl (2010). Nesse documento, os jovens descreveram todas as recordações que tinham sobre as aulas desse componente curricular no Ensino Médio. Após a explicação da forma que o memorial deveria ser realizado, os alunos e as alunas tiveram um período de dois meses para enviar o material produzido para 
os pesquisadores. Durante esse tempo, um estudante não conseguiu finalizar o seu documento e, ao final da pesquisa, quatro jovens entregaram os seus memoriais.

Na perspectiva de Molina Neto e Molina (2010), a pesquisa qualitativa oferece uma oportunidade para os docentes de Educação Física Escolar uma lógica distinta de pensar a sua prática, ressiginificá-la e situá-la em um contexto social mais amplo, possibilitando novas formas de discutir e estabelecer o que é conhecimento válido. Assim, decidimos compreender como que os alunos colaboradores deste estudo perceberam os seus aprendizados nas aulas do componente curricular, sem a pretensão de generalizar essas percepções para o restante da turma.

Na perspectiva de analisar os dados produzidos a partir da escrita dos memoriais descritivos pelos alunos, foi utilizada a análise de conteúdo (BARDIN, 2016). Após a leitura dos memoriais, quatro categorias foram identificadas, sendo elas: manifestações da cultura corporal, saúde e qualidade de vida, marcadores sociais nas práticas corporais e práticas corporais e tecnologia.

Antes da realização da coleta de dados esta pesquisa foi aprovada pelo Comitê de Ética em Pesquisa do Instituto Federal de São Paulo, sob o número 3.240.191.

\section{Resultados e Discussão}

Os resultados dos memoriais descritivos mostraram que os estudantes vivenciaram durante as aulas de Educação Física os jogos, as brincadeiras, as danças, as lutas, os esportes e as ginásticas, refletiram sobre os aspectos sociais, históricos, políticos e econômicos que possuem relação com essas manifestações da cultura corporal, analisaram a relação entre saúde, qualidade de vida e a realização de atividades físicas e produziram um projeto que relacionava o corpo ou as práticas corporais com os conhecimentos da área de Eletrônica. Portanto, encontramos quatro grandes categorias que apontaram para os conhecimentos que os alunos e as alunas do Ensino Médio aprenderam durante as aulas do componente curricular.

\section{$\underline{\text { Manifestações da Cultura Corporal }}$}

Na percepção dos alunos e das alunas que participaram desta pesquisa, o professor de Educação Física tematizou as atividades circenses, as ginásticas, a musculação, as brincadeiras quilombolas, os jogos africanos e indígenas, o kravmagá, o hip hop, a dança de rua, a capoeira, o tchoukball, o jongo, o 
kung fú, o futebol, os esportes para pessoas com deficiência, a musculação e o boxe no Ensino Médio, como podemos identificar nos trechos a seguir.

Aluno 1 - E foi assim que fizemos, já que no primeiro ano praticamos ginástica, fundamentos circenses etc., mas foi no terceiro ano do Ensino Médio, quando voltamos a ter aula com o professor, que vivenciamos o tchoukball: "o esporte da paz".

Aluno 1 - Todos na sala pequena, com cinquenta pessoas dentro, em uma roda apertada, estávamos sem jeito de começar a dançar o jongo, a cabeça quase ainda estava nas provas que acabávamos de terminar, o corpo se levando por simples inércia; quando, junto ao som do berimbau e o pandeiro em minhas mãos, começamos a cantar ladainhas, dar os primeiros passos da jinga, da palma e dos fundamentos básicos. Parecia que meu cérebro voltou ao lugar, pude-me sentir vivo, pude deixar expressar o que a tanto tempo estava comprimido ou negado, me senti feliz.

Aluno 1 - Em outra aula foi um dançarino de hip hop, aprendemos sobre a cultura urbana, e é claro, como fazer os passos básicos. Em outra aula, aprendemos como jogar jogos africanos.

Aluno 2 - São tantas as experiências marcantes que só posso me lembrar de algumas. O jogo de tchoukball, as aulas com os jogos indígenas e africanos, a visita dos quilombolas, a experiência de luta com o professor Marcos, a visita ao museu do futebol.

Aluno 3 - Mas, além disso, o que mais me marcou neste ano foi uma espécie de projeto em que aprenderíamos jogos e brincadeiras "diferentes", e, no final, tivemos de nós mesmos montarmos um jogo ou brincadeira novo. Isso foi marcante, pois aprendemos vários esportes das olimpíadas para pessoas com deficiência, como, por exemplo, um tipo de basquete sentado e um outro esporte para cegos.

Aluno 3 - Foi um trabalho que gostei muito de fazer, pois pude mostrar para meus colegas uma coisa que gosto muito na minha vida pessoal, o kravmagá, uma técnica de defesa pessoal israelense.

A partir desses relatos, podemos mencionar que os alunos e as alunas tiveram experiências com uma diversidade de práticas corporais durante as aulas de Educação Física no Ensino Médio. Nesse 
sentido, destacamos que a ampliação das manifestações da cultura corporal vivenciadas pelos estudantes rompe com a hegemonia das práticas esportivas nas aulas do componente curricular, movimento que se fortaleceu no século XX e ficou conhecido como esportivização da Educação Física Escolar (BRACHT; GONZÁLEZ, 2014).

Além disso, a vivência dos gestos de diversificadas práticas corporais nas aulas de Educação Física é defendida pelas propostas pedagógicas do componente curricular inspiradas na teorização curricular crítica e pós-crítica em currículo, principalmente quando essas experiências são tematizadas para que os jovens estudantes analisem a cultura das danças, lutas, ginásticas, esportes, jogos e brincadeiras (CASTELLANI FILHO et al., 2009; KUNZ, 2006; NEIRA; NUNES, 2008).

Por conta disso, defendemos que apenas vivenciar as danças, as lutas, as ginásticas, os esportes, os jogos e as brincadeiras não garante que os jovens possam conhecer e ressignificar os conhecimentos históricos, sociais, econômicos, políticos, biológicos e fisiológicos que perpassam as práticas corporais.

\section{$\underline{\text { Marcadores sociais (gênero, etnia, classe social, geração) nas práticas corporais }}$}

Os discentes refletiram sobre os marcadores sociais de gênero, etnia e classe social relacionados com as práticas corporais, que resultaram na visibilidade e discussão de como é a participação feminina no esporte e a diferença salarial entre homens e mulheres, sendo citada como referência a atleta Serena Willians. Além disso, foi problematizado o machismo nas práticas corporais, o preconceito racial no esporte, os jogos e as brincadeiras de comunidades quilombolas, a cultura das práticas corporais, a realidade dos espaços públicos de lazer e a relação entre esporte e capital econômico, como podemos observar nos trechos retirados dos memoriais descritivos.

Aluno 1 - Pelo que me lembro, fizemos "rodas de conversas" e escrevemos sobre a participação feminina no esporte, sobre as diferenças salariais e de divulgação entre o esporte masculino e o feminino, refletindo sobre a participação das meninas nas "aulas de Educação Física. Umas das primeiras atividades que fiz foi sobre a participação feminina no tênis e preconceito racial no esporte. Escrevi uma crônica junto com minha colega sobre a Serena e a Vênus Willians. Expondo a diferença nos prêmios de campeonatos de tênis e os comentários ofensivos a Serena Willians que é negra. 
Aluno 1 - A história dos quilombos no Brasil nos apresentou as dificuldades que vivem atualmente na demarcação de terras, as plantas medicinais utilizadas por eles, os artesanatos e brincadeiras locais, que são acompanhadas de uma música.

Aluno 1 - O mais importante: pude conhecer melhor minha cultura corporal, trazendo sentido e motivação para a prática de atividades físicas. A interdisciplinaridade, a crítica aos problemas da sociedade e a pesquisa nos faz mais inteligentes, aprendendo para a vida, e para melhoria do mundo a nossa volta

Aluno 2 - Lembro-me de um período em que estudava no conservatório de música. $\mathrm{Na}$ ocasião comentei com um professor que não conseguia entender dança como uma manifestação artística, não era capaz de enxergar movimentos ordenados como reflexo de sentimentos, e fiquei ainda algum tempo sem entender. Arrisco dizer que talvez só consegui ter esta percepção em uma aula sobre capoeira, pela primeira vez enxerguei sobre o corpo de Fabinho o peso de uma cultura, de uma história esquecida pelas elites intelectuais.

Aluno 3 - Em 2018, meu segundo ano tendo aula com o professor e meu terceiro ano no instituto, tivemos várias práticas realizadas também com o intuito de mostrar diferentes culturas. Tiveram dias que trabalhamos com jogos típicos de vários lugares diferentes, e aprendemos sobre as respectivas culturas e alguns costumes. Além disso, o professor conseguiu montar várias oficinas nas quais levou profissionais/pessoas que viviam com o que ele queria nos apresentar para que conhecêssemos mais do que vemos num simples artigo de internet; ele nos mostrou a realidade. Dentre essas oficinas, posso citar como exemplo a oficina de boxe, onde um professor do instituto que também é boxeador levou seus materiais e nos contou histórias de sua carreira, a oficina de capoeira, a de dança de rua, entre outras.

Aluno 3 - Ainda nesse ano, fizemos uma charge que deveria se relacionar com a cultura corporal de movimento (esportes, danças, lutas, etc.), mas com um caráter crítico; seja mostrando o feminismo ou qualquer outra luta social ou coisa do tipo.

Aluno 4 - O professor sempre tentava trazer alguns jornais que tinham manchetes relacionadas principalmente com esporte e a situação política do país (principalmente durante o primeiro ano do ensino médio, em 2016), comecei a me interessar muito em 
leituras científicas e sempre que eu podia pesquisava a respeito de alguns assuntos discutidos em sala na Scielo ou no Google Acadêmico.

Aluno 4 - Me recordo plenamente do momento em que conheci em sala de aula a ilustre e incrível figura de Serena Willians, como poderia ser tão extraordinária e mesmo assim não tão conhecida e comentada por nós? A resposta é simples, o mundo e em consequência o esporte são machistas. As mulheres não estão inclusas dentro do contrato social, o mundo é regido por homens e para homens. Antes de tudo, um contrato sexual foi firmado e desde então as mulheres são vistas como propriedade. Isso se reflete em todas as áreas, o esporte é machista e não comemora muito menos propaga os feitos das mulheres. Discutir feminismo e principalmente o feminismo negro me impactou muito como aluna, através de muitas coisas que ousei ler pude tomar mais conhecimento e entender melhor como as mulheres são excluídas socialmente na maior parte do tempo e vistas como um puro pedaço de carne até mesmo no esporte.

Ressaltamos que no Brasil o conhecimento disseminado pelos docentes nas escolas possui predominantemente perspectivas e identidades da cultura europeia e estadunidenses (MOREIRA, 2001). Assim, nas aulas de Educação Física, práticas corporais, como o futebol, o vôlei, o handebol e o basquetebol, são temas hegemônicos. Portanto, quando os jovens vivenciam a gestualidade de manifestações da cultura corporal de diferentes culturas e refletem sobre as relações de gênero, raça e classe social que se relacionam com essas práticas, eles e elas podem realizar uma leitura de mundo mais ampla da realidade, reconhecendo e valorizando as diferenças entre as pessoas em uma sociedade multicultural.

Na nossa perspectiva, fazer a leitura de mundo sobre a cultura das práticas corporais significa estimular que o estudante conquiste uma visão crítica e dinâmica da realidade, permitindo que ele desvele o seu cotidiano a partir dos conhecimentos construídos e reconstruídos nas aulas, possibilitando o sermais (FREIRE, 2016).

Nesse contexto, a partir das reflexões realizadas por Oliveira e Candau (2010), consideramos que os sistemas de ensino e o espaço acadêmico privilegiaram apenas os conhecimentos produzidos pelo Ocidente como os únicos verdadeiros e legítimos, proporcionando uma espécie de racismo epistêmico. Para modificar essa realidade, os professores e as professoras de Educação Física precisam tematizar práticas corporais de diferentes culturas, além de problematizar os conhecimentos relacionados com essas 
manifestações da cultura corporal, desenvolvendo uma pedagogia intercultural e antirracista em suas aulas.

Assim, um professor ou uma professora de Educação Física comprometidos com a promoção da equidade, justiça social e cidadania, ao tematizar as manifestações da cultura corporal, questiona os marcadores sociais de classe, etnia, gênero, religião e geração nelas presentes (NEIRA, 2010). A partir das percepções dos alunos e das alunas sobre as aulas de Educação Física, apontamos que as aulas do componente curricular no Ensino Médio inspiradas pela pedagogia intercultural e antirracista, pode oportunizar debates que estimulem os jovens a se posicionar contra as desigualdades sociais e valorizar as diferenças culturais na sociedade contemporânea.

\section{$\underline{\text { Saúde e Qualidade de Vida }}$}

Os discentes que participaram do estudo descreveram muitas experiências educativas que problematizavam a saúde e a qualidade de vida durante as aulas de Educação Física. Nesse contexto, os temas abordados foram: a relação do esporte com a saúde, os efeitos colaterais dos anabolizantes nos esportes (calvície, necrose muscular, interrompimento da epífise óssea nas crianças de treinamento exagerado, apodrecimento dos músculos), a corrupção e o doping que existe no meio esportivo, a realização de uma alimentação saudável, a relação entre o padrão de beleza imposto pela sociedade contemporânea e os transtornos alimentares (bulimia), os programas milagrosos de emagrecimento que aparecem nas revistas e nas propagandas, a elaboração de um treinamento de musculação e os benefícios das atividades físicas em pacientes com depressão. Abaixo, destacaremos algumas frases descritas pelos estudantes.

Aluno 1 - "Esporte não é saúde", ouvimos isso tantas vezes do professor que até me cansa escrever aqui. $\mathrm{O}$ esporte é levar o corpo ao limite, e por que fazer isso? Talvez porque o fim do esporte seja o dinheiro que ele traz.

Aluno 1 - Apreendemos os efeitos dos anabolizantes: calvície, necrose muscular; o interrompimento da epífise óssea nas crianças de treinamento exagerado, etc.

Aluno 1 - Ele nos apresentou o nome dos músculos do corpo e como ter uma alimentação saudável. 
Aluno 1 - Casos de bulimia, programas milagrosos de emagrecimento, agredindo o psicológico e o corpo, principalmente de adolescentes.

Aluno 1 - Buscando a saúde, montamos com o professor planos de treinamento moderado.

Aluno 2- Ao invés de me sentir excluído na aula me senti acolhido, e ainda se disponibilizou em olhar meus exames e me passar um treino de musculação.

Aluno 3 - Em 2016, aprendemos bastante sobre a utilização de anabolizantes e seus efeitos colaterais, podendo até chegar a problemas muito complicados como, por exemplo, o apodrecimento dos músculos, bem como devemos realizar atividades físicas da maneira correta, eficiente e saudável. Além da parte biológica que aprendemos com relação aos esportes e exercícios que praticamos.

Aluno 3- Utilizando a própria academia da escola, o professor nos mostrou todos os equipamentos, como deveriam ser feitos os exercícios em cada um e qual parte do corpo cada aparelho influencia.

Aluno 4 -A proposta era que os grupos realizassem um TCC. Eu e meus colegas trabalhamos com o intuito de estudar a influência das atividades físicas em pacientes com depressão.

Aluno 4- Pudemos desconstruir conceitos de que a depressão é frescura estudando como o cérebro de um paciente acometido por este mal funciona e da mesma forma pesquisamos sobre como as atividades físicas podem fazer parte do tratamento, trazendo inúmeros benefícios. 
Bracht (2019) afirma que a relação da escola com o tema da saúde legitimou a função social da Educação Física na Educação Básica durante muitas décadas. Na visão do autor, os professores e as professoras do componente curricular reproduziram um discurso médico-higienista sobre a relação entre atividade física e a prevenção dos grandes riscos à saúde que representam o sedentarismo, as doenças crônico-degenerativas e a obesidade. Assim, a forma de abordar a saúde nas aulas de Educação Física estava mais relacionada com uma questão fisiológica do que pedagógica.

Ao analisar as percepções dos discentes relacionadas ao que aprenderam sobre qualidade de vida e saúde nas aulas de Educação Física, podemos afirmar que uma concepção ampliada dessa temática foi abordada nessa experiência educativa, principalmente pela descrição dos estudantes que o esporte de alto nível não pode ser considerado saudável, por levar o corpo dos atletas ao extremo; a compreensão dos efeitos colaterais causados pela utilização de anabolizantes; a relação entre o padrão de beleza e os transtornos alimentares; a realização de um treinamento de musculação e os benefícios da atividade física para o tratamento da depressão.

Portanto, o docente de Educação Física possibilitou que os alunos e as alunas questionassem o significado de uma vida saudável e compreendessem, de forma crítica, quais são os condicionantes sociais que interferem no processo saúde-doença (BRACHT, 2019).

Ainda em diálogo com Oliveira, Martins e Bracht (2015) e Dias et al. (2016), defendemos que o conceito de saúde precisa ser debatido em uma concepção mais ampla e sistêmica durante as aulas de Educação Física, tanto no Ensino Fundamental quanto no Ensino Médio.

\section{Práticas Corporais e Tecnologia}

O último tema percebido pelos estudantes sobre os conhecimentos desenvolvidos durante as aulas de Educação Física foi a relação entre as práticas corporais e a tecnologia. O docente do componente curricular estimulou que os discentes criassem projetos, relacionando as manifestações da cultura corporal ou corpo com a sua área de formação profissional, já que os jovens realizavam o curso de Eletrônica integrado ao Ensino Médio.

Aluno 1 - Após a prática de análise de problemas e soluções da Educação Física na sociedade, fomentadas nas aulas, poder buscar com o que sabemos, e em específico com a bagagem da sala: técnicos em Eletrônica. Aplicar nossos conhecimentos, criativamente 
em protótipos para melhoria da Educação Física ou saúde na sociedade, foi essencial para nossa formação. Ao meu ver, realizar essa atividade, foi muito importante, pois tivemos que exercitar, pensar e repensar, como poderíamos ajudar tecnologicamente a sociedade.

Aluno 4 - Durante o terceiro ano do ensino médio, os alunos de eletrônica que tem a disciplina de Educação Física são submetidos a elaboração de um projeto eletrônico que envolva as práticas corporais ou o corpo. A iniciativa em si é muito interessante e ambiciosa, trazer nossos conhecimentos do técnico para que algo relacionado à Educação Física seja elaborado e ajude as pessoas de alguma forma.

Frigotto (2019) menciona que o Ensino Médio integrado aos cursos de educação profissional deve ser organizado por um ensino que não separa e sim integra, em uma totalidade concreta, nas suas dimensões humanísticas, técnicas, culturais e políticas e que também não estabelece dicotomia entre os conhecimentos da formação geral e da formação técnica.

Destacamos que estudos conduzidos por Silva, Oliveira e Silva e Molina Neto (2016) e Metzneret al. (2017) analisaram a finalidade do componente curricular nos cursos técnicos integrados aos Ensino Médio, mostrando o compromisso dos pesquisadores da área em compreender a especificidade da Educação Física nas escolas federais.

Ao pensar na função social do componente em cursos de educação profissional integrado ao médio, projetos de integração curricular podem proporcionar a valorização da Educação Física nessas instituições de ensino, trazendo efetivamente o trabalho como princípio educativo e a pesquisa como prática pedagógica.

Nesse contexto, ao relacionar os conteúdos específicos da área de Educação Física com a área de formação profissional dos estudantes, o docente organizou a sua prática político-pedagógica de acordo com a fundamentação teórica dos cursos que integram a formação profissional e a propedêutica no Ensino Médio. Assim, ao rememorar sobre as percepções que tiveram sobre as aulas de Educação Física nesse ciclo de escolarização, os alunos e as alunas pesquisados ressaltaram essas atividades de ensino nos seus memoriais descritivos. 


\section{Considerações Finais}

Esta pesquisa mostrou que os estudantes do Ensino Médio vivenciaram os gestos das práticas corporais de diferentes culturas, debateram e analisaram os aspectos sociais, econômicos, políticos e históricos relacionados com as manifestações da cultura corporal, refletiram sobre a relação entre a atividade física, a saúde e a qualidade de vida de forma ampliada e integraram os conhecimentos da Educação Física com a área de Eletrônica, possibilitando outras formas de ver e entender o mundo.

Também é possível mencionar que esse grupo de estudantes participou de aulas de Educação Física influenciadas pelas teorias críticas e pós-críticas (SILVA, 2015), em que o objetivo central do componente curricular está relacionado com a tematização das práticas corporais e a problematização dos marcadores sociais que atravessam as manifestações da cultura corporal.

Temos clareza que não é possível generalizar os dados produzidos nesta pesquisa para todas as instituições escolares brasileiras, até por conta do número reduzido de estudantes que participaram do estudo. Entretanto, a produção acadêmica da Educação Física começa a mostrar que outras práticas corporais estão sendo tematizadas e diversificados conhecimentos problematizados nas aulas do componente curricular na Educação Básica, possibilitando que as crianças, adolescentes, adultos e jovens reconheçam a importância dessas experiências para a sua formação humana.

Especificamente sobre a percepção dos discentes sobre as aulas de Educação Física, essa nova realidade já pode ser observada nos estudos de Guarinon (2016), Oliveira Júnior (2017), Alves et al. (2018) e Silva, Souza e Martins (2019). Entretanto, todas essas pesquisas foram realizadas com alunos e alunas que estavam no Ensino Fundamental. Especificamente nos Institutos Federais, o estudo conduzido por Sá (2019) aponta para uma visão mais crítica sobre as aulas do componente curricular dos estudantes do Ensino Médio.

Sugerimos que novos estudos possam ser conduzidos nas instituições federais de ensino, onde pesquisadores e pesquisadoras possam utilizar outros instrumentos de pesquisa, tais como entrevista, grupo focal e observação das aulas, criando a possibilidade de compreender sobre os aprendizados que os estudantes adquirem nas aulas do componente de forma mais ampla e, por consequência, produzir novos conhecimentos sobre as aulas de Educação Física no Ensino Médio. 


\section{Referências}

AGUIAR, Camila dos Anjos; NEIRA, Marcos Garcia. O ensino da Educação Física: dos métodos ginásticos à perspectiva cultural. In: NEIRA, Marcos Garcia. Educação Física Cultural. São Paulo: Blucher, 2016. p. 69-86.

ALENCAR FILHO, Antonio. A cultura corporal afro e afro-brasileira como identidade cultural: no Instituto Federal do Pará - campus Tucuruí. In: SARMENTO, Maria do Perpétuo Socorro. Experiências de intervenção pedagógica na Educação Física Escolar. Goiânia: Editora Espaço Acadêmico, 2018. p. 17-38.

ALVES, Luana Tavares de Oliveira et al. Prática pedagógica inovadora nas aulas de Educação Física Escolar: percepções de estudantes e de um professor. Biomotriz. v. 12, n. 2, p. 81-101, 2018.

BARDIN, Laurence. Análise de Conteúdo. $3^{\text {a }}$ ed. Lisboa, Edições 70, 2016.

BARRA, Andréa de Oliveira. Compartilhando Experiências nas aulas de Educação Física no CEFET Campus Nepomuceno. In: NOGUEIRA, Valdilene Aline; MALDONADO, Daniel Teixeira; FARIAS, Uirá de Siqueira. Educação Física Escolar no Ensino Médio: a prática pedagógica em evidência 2. Curitiba: CRV, 2018. p. 147-158.

BRACHT, Valter. A constituição das teorias pedagógicas da Educação Física. Cadernos Cedes. Ano XIX, n. 48, p. 69-88, 1999.

BRACHT, Valter. A Educação Física Escolar no Brasil: o que ela vem sendo e o que pode ser. Ijuí: Unijuí, 2019.

BRACHT, Valter; GONZÁLEZ, Fernando Jaime. Educação Física Escolar. In: GONZÁLEZ, Fernando Jaime; FENSTERSEIFER, Paulo Evaldo. Dicionário Crítico da Educação Física. $3^{\mathrm{a}}$ ed. Ijuí: Unijuí, 2014. p. 241-247.

CASTEllani FILHO, Lino. et al. Metodologia do Ensino da Educação Física. 2a ed. São Paulo: Cortez, 2009.

DIAS, Graziany Penna et al. Pedagogia histórico-crítica, cultura corporal, saúde e atividade física: aspectos teóricos e metodológicos para o Ensino Médio. Nuances: estudos sobre Educação. Presidente Prudente-SP, v. 27, n. 1, p. 165-186, 2016.

DINIZ, Irlla Karla dos Santos. Dança nas aulas de Educação Física: dando voz ao corpo no IFSP Capivari. In: NOGUEIRA, Valdilene Aline; MALDONADO, Daniel Teixeira; FARIAS, Uirá de Siqueira. Educação Física Escolar no Ensino Médio: a prática pedagógica em evidência 2. Curitiba: CRV, 2018. p. 133-146.

FREIRE, Paulo. Conscientização. São Paulo: Cortez, 2016.

FRIGOTTO, Gaudêncio. Projeto societário, ensino médio integrado e educação profissional: o paradoxo da falta e sobra de jovens qualificados. In: FRIGOTTO, Gaudêncio. Institutos Federais de Educação, 
Ciência e Tecnologia: relação com o ensino médio integrado e o projeto societário de desenvolvimento. Rio de Janeiro: LPP-UERJ, 2018. p. 41-62.

GIL, Antônio Carlos. Métodos e Técnicas de Pesquisa Social. $6^{\text {a }}$ ed. São Paulo: Atlas, 2008.

GUARINON, Poliani Claro. Representações sociais e o currículo da Educação Física: com a palavra os alunos. Dissertação (mestrado). São Paulo: Escola de Educação Física e Esporte da Universidade de São Paulo, 2016.

KUNZ, Elenor. Transformação didático-pedagógica do esporte. 7ª ed. Ijuí: Unijuí, 2006.

MALDONADO, Daniel Teixeira. Professores e professoras de Educação Física progressistas do mundo, uni-vos!Curitiba: CRV, 2020.

MALDONADO, Daniel Teixeira; NEIRA, Marcos Garcia. Didática(s) da educação física escolar: colocando em evidência histórias que não se contam. Anais do II Encontro Pensando a Educação Física Escolar. Minas Gerais: IFMG e UFMG, v. 1. p. 70-78, 2019.

METZNER, Andreia Cristina et al. Contribuição da Educação Física para o Ensino Médio: estudo a partir da prática docente de professores de Institutos Federais. Motrivivência. Florianópolis/SC, v. 29, n. 52, p. 106-123, 2017.

MOLINA NETO, Vicente; MOLINA, Roseane Kreusburg. Pesquisas qualitativas em Educação Física Escolar: a experiência do F3P-EFICE. In: MOLINA NETO, Vicente; BOSSLE, Fabiano. O ofício de ensinar e pesquisar na Educação Física Escolar. Porto Alegre: Sulina, 2010. p. 9-36.

MOREIRA, Antônio Flávio Barbosa. A recente produção científica sobre currículo e multiculturalismo no Brasil (1995-2000): avanços, desafios e tensões. Revista Brasileira de Educação, n. 18, p. 65-81, 2001.

NEIRA, Marcos Garcia. Por dentro da sala de aula: conversando sobre a prática. 2. ed. São Paulo: Phorte, 2009.

NEIRA, Marcos. Educação Física cultural: inspiração e prática pedagógica. $2^{a}$ ed. Jundiaí, SP: Paco, 2019.

NEIRA, Marcos Garcia; NUNES, Mario Luiz Ferrari. Pedagogia da cultura corporal: críticas e alternativas. $2^{a}$. ed. São Paulo: Phorte, 2008.

OLIVEIRA, Fernando Dias; MALDONADO, Daniel Teixeira. Educação Física Escolar no Ensino Médio: estímulo ao pensamento crítico e à formação da cidadania dos estudantes. In: MALDONADO, Daniel Teixeira; NOGUEIRA, Valdilene Aline; FARIAS, Uirá de Siqueira. Os professores como intelectuais: novas perspectivas didático-pedagógicas na Educação Física Escolar brasileira. Curitiba: CRV, 2018. p. 265-280.

OLIVEIRA, Luiz Fernandes; CANDAU, Vera Maria Ferrão. Pedagogia decolonial e educação antirracista e intercultural no Brasil. Educação em Revista. Belo Horizonte, v. 26, n. 1, p. 15-40, 2010. 
OLIVEIRA,VictorJoséMachadode;MARTINS,IzabellaRodrigues;BRACHT,Valter. Projetos e práticas em Educação para a saúde na Educação Física Escolar: possibilidades! Revista da Educação Física/UEM, Maringá, v. 26, n. 2, p. 243-255, 2015.

OLIVEIRA JÚNIOR, Jorge Luiz. Significações sobre o currículo cultural da Educação Física: cenas de uma escola municipal paulistana. Dissertação (mestrado - Programa de Pós-Graduação em Educação). Faculdade de Educação da Universidade de São Paulo, 2017.

SÁ, Kátia Regina. Currículo do Ensino Médio integrado do IFMG: a partitura, a polifonia e os solos da Educação Física. Tese de Doutorado. Faculdade de Educação, Universidade de São Paulo, 2019.

SILVA, Adriano Gonçalves. Trekking como conteúdo da Educação Física no Ensino Médio: diálogos entre cultura, educação e meio ambiente. In: MALDONADO, Daniel Teixeira; NOGUEIRA, Valdilene Aline; FARIAS, Uirá de Siqueira. Educação Física Escolar no Ensino Médio: a prática pedagógica em evidência. Curitiba: CRV, 2018. p. 143-157.

SILVA, Bruna Saurin; SOUZA, Ana Cláudia Ferreira; MARTINS, Mariana Zuaneti. Desafiando o abismo tradicional: uma aproximação entre práticas inovadoras e o modelo de educação esportiva no âmbito da educação Física Escolar. Revista Brasileira de Ciências do Esporte, 2019. https://doi.org/10.1016/j.rbce.2019.04.003.

SILVA, Lisandra de Oliveira; DIEHL, Vera Regina Oliveira. Da construção dos procedimentos metodológicos à produção de conhecimento: compartilhando experiências a partir da narrativa escrita. In: MOLINA NETO, Vicente; BOSSLE, Fabiano. O ofício de ensinar e pesquisar na Educação Física Escolar. Porto Alegre: Sulina, 2010. p. 94-122.

SILVA, Marlon André; OLIVEIRA E SILVA, Lisandra; MOLINA NETO, Vicente. Possibilidades da Educação Física no Ensino Médio Técnico. Movimento. Porto Alegre, v. 22, n. 1, p. 325-336, 2016.

SILVA, Tomaz Tadeu. Documentos de identidade: uma introdução às teorias do currículo. $3^{\text {a }}$ Ed. Belo Horizonte: Autêntica, 2015.

TAVARES, Marie Luce. Se ela dança, eu... e quem mais dança? - a dança como conteúdo da Educação Física e o convite à discussão de gênero. In: MALDONADO, Daniel Teixeira; NOGUEIRA, Valdilene Aline; FARIAS, Uirá de Siqueira. Educação Física Escolar no Ensino Médio: a prática pedagógica em evidência. Curitiba: CRV, 2018. p. 213-230.

\section{Como citar este artigo}

BASTOS, J. M. V.; MALDONADO, D. T. Percepções dos estudantes do Ensino Médio sobre os conhecimentos aprendidos nas aulas de Educação Física Escolar. Revista Kinesis, Santa Maria, v.38, p.01-17, 2020.

* O presente trabalho não contou com apoio financeiro de nenhuma natureza para sua realização. 